\section{References}

Baumslag, N., Edelstein, T., and Metz, J. (1970). British Medical fournal, 1,16 .

1, 16. G., and Spray, G. H. (1969). British fournal of Nutrition, 23, 665.

Chanarin, I., Rothman, D., and Berry, V. (1965). British Medical fournal, $1,480$.

Chanarin, I., Rothman, D., Ward, A., and Perry, J. (1968). British Medical Fournal, 2, 390.

de Leeuw, N. K. M., Lowenstein, L., and Hsieh, Y.-S. (1966). Medicine, $45,291$.

Gross, S., Keefer, V., and Newman, A. J. (1965). Lancet, 2, 744.

Iyengar, L., and Apte, S. V. (1970). American fournal of Clinical Nutrition,
Lowenstein, L., Brunton, L., and Hsieh, Y.-S. (1966). Canadian Medical Association fournal, 94, 636.

Temperley, I. J., Meehan, M. J. M., and Gatenby, P. B. B. (1968). British Fournal of Haematology, 14, 13.

Velez, H., Restreppo, A., Bustamente, J., and Vitale, J. J. (1965). American fournal of Clinical Nutrition, 16, 383.

Vitale, J. J., Restreppo, A., Velez, H., Riker, J. B., and Hellerstein, E. E. (1966). Fournal of Nutrition, 88, 315 .

Vitale, J. J., Streiff, R. R., and Hellerstein, E. E. (1965). Lancet, 2, 393.

Vossough, P., Leikin, S., and Purugganan, G. (1968). Pediatric Research, 2

Willoughby, M. L. N. (1967). British fournal of Haematology, 13, 503.

\title{
Diabetes after Removal of Insulin Tumours of Pancreas: A Long-term Follow-up Survey of 11 Patients
}

\author{
D. C. DUNN
}

British Medical fournal, 1971, 2, 84-87

\section{Summary}

Eleven patients who had islet cell tumours of the pancreas removed over a 20 -year period were reviewed. Two had died, one in the postoperative period and one 10 years postoperatively. The remaining nine were traced and eight of them were personally interviewed and tested. All nine were well and free from recurrent symptoms. Five of the eight had evidence of subnormal insulin production in response to oral glucose. Glucose tolerance was impaired in three. Minor anomalies were found in the electroencephalograms of all these patients and major abnormalities in two.

The results of this survey suggest that other patients who have had islet cell tumours removed may now have unsuspected diabetes.

\section{Introduction}

Though it is 40 years since the association of islet cell tumours of the pancreas with clinical hypoglycaemia was established, little is known about the patients who have had tumours removed. Follow-up information is mainly limited to whether they have had recurrent hypoglycaemic attacks or have remained well.

\section{Subjects and Methods}

Since 194711 patients have had islet cell tumours excised at St. Bartholomew's Hospital. These were reviewed and those living were traced. Eight were personally interviewed and examined. Information was obtained from one patient by letter. The period of follow-up ranged from six months to 18 years, five patients having survived over 10 years. The operations carried out are listed in the Table.
St. Bartholomew's Hospital, London E.C.1

D. C. DUNN, F.R.C.S., Senior House Officer (Present address: Addenbrooke's Hospital, Cambridge CB2 2AH)
At follow-up the facts of each recorded case history were checked with the patient. Where possible the relatives and general practitioners were questioned about the patient's past and present mental health. Over a period of three hours a glucose tolerance test (using $50 \mathrm{~g}$ of glucose dissolved in water taken orally) was performed; serum samples were taken for insulin levels; and electroencephalograms were recorded at different blood sugar levels. The serum calcium was also measured.

Blood glucose was measured by AutoAnalyzer. The method was a modification of the Technicon ferricyanide reduction method, which has given results very close to a glucoseoxidase method. Serum insulins were measured by an immunoassay method using the Amersham kit based on the method of Hales and Randle (1963). Control values for the insulin and glucose levels, supplied by the laboratories carrying out the estimations, are shown in Figs. 1 and 2. The electroencephalograms were interpreted by Dr. J. $H$. Margerison.

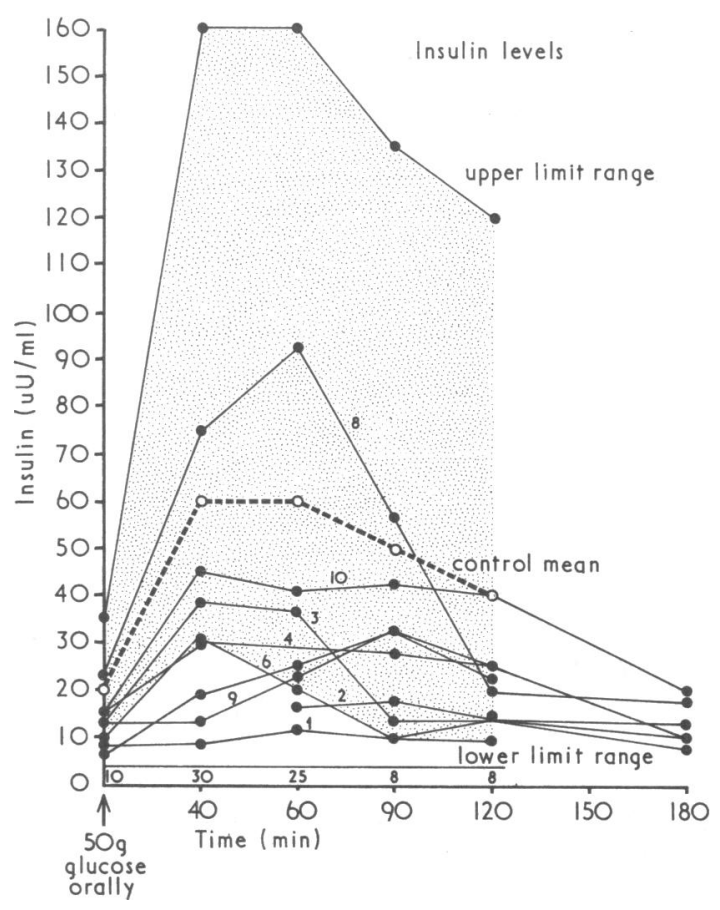

FIG 1 -Insulin responses to $50 \mathrm{~g}$ oral glucose. Numbers refer to cases listed in the Table. 


\section{Results}

General.-Two of the 11 patients were dead. One died three days postoperatively from bronchopneumonia. The other survived 10 years after removal of the tumour, with a hemiplegia which had followed a severe hypoglycaemic attack. She had had no hypoglycaemic attacks after the operation and died suddenly from subarachnoid haemorrhage. Of the other nine patients none had had recurrent attacks and all but one were well. One patient, who had moved to Malaya, had recently undergone an operation for "upper abdominal sepsis." After

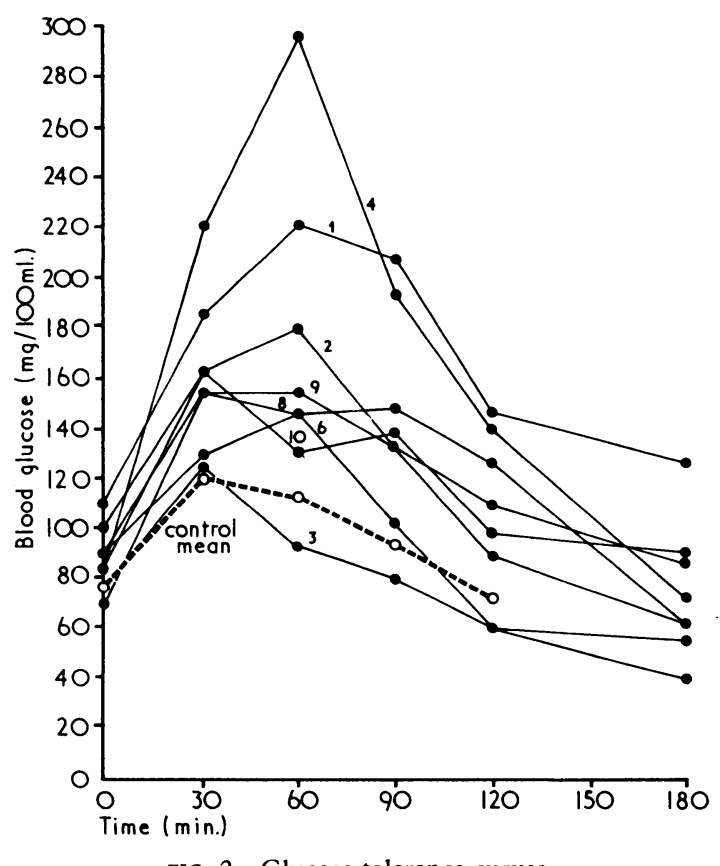

all the investigations had been completed one patient (Case 10) developed further attacks and had a recurrent insulinoma (carcinoma) removed. This occurred eight months after the original operation. Two years after the survey she was still the only patient who had recurrent attacks of hypoglycaemia.

Insulin Production (see Figs. 1 and 2).-Of eight patients tested five had a diminished insulin response to $50 \mathrm{~g}$ of oral glucose. Oral glucose tolerance was grossly impaired in one and diminished in two. As a group these eight patients had significantly lower insulin level responses than those of 20 controls. This finding was unexpected and is discussed below.

Postoperative Complications (see Table).-The search for a history of postoperative sepsis was stimulated by the insulin results. No comparable figures are available from other series. Five patients took more than three weeks to obtain dry abdominal wounds, and four of these had pancreatic fistulae lasting one month or more. The occurrence of these complications was not related to the extent of the pancreatic resection, to the site of the adenoma, or to any individual surgeon. It is of interest that the patient who died in the postoperative period had evidence of pancreatic necrosis at the operation site. The patient who died 11 years postoperatively had fibrous scars in the region of the common bile duct in the head of the pancreas, but the rest of the gland was normal.

Post-hypoglycaemic Encephalopathy.-Two patients (Cases 5 and 9) had clinical evidence of brain damage in the form of hemiplegias which followed severe hypoglycaemic attacks. Both had remained unconscious for more than 48 hours in spite of restoration of normoglycaemia. None of the other patients had any neurological signs, and all were considered by themselves and by their relatives and doctors to be "normal." None had had treatment in mental hospitals, and the one (Case 1) who had been treated for anxiety had a long family history of this condition and had been anxious all his life. Serial electroencephalography was carried out on all patients while fasting and during the glucose tolerance test. These were definitely abnormal in two-Case 9 had a clinically apparent hemiplegia and Case 10 later developed a recurrent tumour, as previously mentioned. All other records showed minor abnormalities. For instance, posterior temporal slow waves and occasional sharp waves were seen in most of the electroencephalograms.

\section{Discussion}

Moss and Rhoads (1960) reviewed 450 cases of benign islet cell tumours before 1958 which had been reported in the world literature- $84 \%$ of the patients were alive and well after the last follow-up reported, but only eight patients had been followed up for more than 10 years. Of those who survived $92 \%$ were relieved of hypogylcaemic symptoms. Of the 356 patients listed two were noted to have developed diabetes and two suffered from pancreatitis. Five showed neurological lesions. The Mayo series has been well documented by Breidahl et al. (1955), Remine et al. (1960), Priestley (1962), and Laroche et al. (1968). In the latter article $96 \%$ of 112

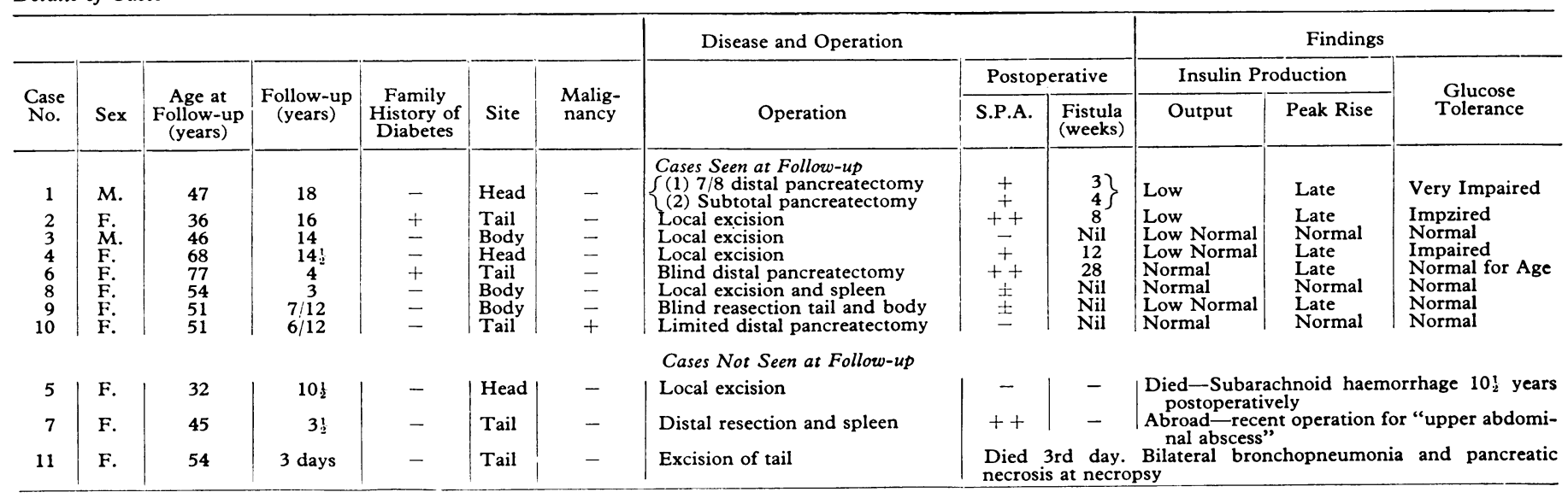


patients with adenomas were free from recurrent symptoms at follow-up, all but six of these being more than two years after operation. The incidence of cerebral complications or diabetes was not given. Of 19 cases of islet cell tumours from the Lahey clinic 16 patients were described as cured, three for more than 10 years postoperatively, and three had become diabetics, one of whom had a postoperative pancreatic fistula (Marshall, 1958). Soper et al. (1968) reviewed 12 cases of hyperinsulinism from Iowa, among them were seven patients with adenomas-five were described as well and two had died. Immediate postoperative complications were described in three patients and one was said to be diabetic after the excision of two adenomas.

A few papers have been written specifically about follow-up results, Markowitz et al. (1961) followed up six of Whipple's original cases of islet cell tumours excised 25 years previously. They found that three out of six had gastrointestinal bleeding, five had pronounced deterioration of their mental processes, and two were diabetic. They felt that the occurrence of diabetes in two of their six patients was a chance finding. Søgaard and Aargard (1968) reviewed all 30 cases of hyperinsulinism in the Scandinavian literature; among them were 20 cases of benign insulinoma. Eight were described as "cured" and two as "improved." Two were diabetic. Pancreatic fistulae were mentioned as postoperative complications in two, and a wound abscess in one. No reports on insulin levels have been found in late follow-up cases, though Klink et al. (1967) described a case with high insulin levels 15 weeks after removal of an islet cell tumour. These appeared to be gradually falling towards normal on serial testing.

As these examples show, diabetes is mentioned as a late complication in many of the published series. No overall incidence is given, and in the main the diabetes is dismissed as an incidental finding.

In comparison with the other series all the patients in the present study had remained well and free from recurrent attacks, with the exception of Case 10 . That is to say, $82 \%$ of the series were "cured," and up to the time of this investigation none was "diabetic." It is against this background of good health that the results must be considered.

\section{DIABETES}

The finding that many of these patients had abnormal insulin production postoperatively is of interest. Two explanations are possible, and both are speculative.

\section{Common Pathogenesis}

A number of authors have suggested a relationship between diabetes and insulinomas. Conn (1946) wondered whether the two conditions might have a common pathogenesis. Insulinomas appearing in known diabetics have been reported by Bielchowski (1932), Bickel et al. (1935), Van Der Sar et al. (1956), Gittler et al. (1958), and Knight (1967). Like et al. (1965) studied a strain of hereditary diabetic mice which spontaneously developed insulin-secreting islet cell tumours causing the diabetes to be ameliorated. The authors speculated that these mice had a congenital high peripheral resistance to insulin action, and that this resulted in an increased stimulus to insulin production and eventually to adenoma formation.

There is, however, no evidence of insulin "resistance" in our series. The patients had a low rather than a high insulin production, and there was no evidence that they required higher than normal insulin levels to effect removal of glucose from the blood. The picture was more of patients whose source of insulin was not functioning adequately.

\section{Pancreatic Damage}

All these patients have had pancreatic surgery, and damage to the pancreas might account for the findings. Low insulin outputs are known to occur after chronic pancreatitis, though it is generally held that very extensive pancreatic damage is necessary before diabetes results (Schumacker, 1940; Cattell and Warren, 1953).

It was not considered justified to re-examine these fit patients by subjecting them to prolonged pancreatic function tests, so no precise assessment of pancreatic function was made. Only one patient (Case 1) gave a history suggestive of pancreatic insufficiency (steatorrhoea). The calcium levels were within normal limits in all cases. Nevertheless, some assessment of pancreatic damage could be made from the history and postoperative notes. The relationship between this damage and the insulin production is shown in the Table. It can be seen that all the patients with low insulin production had had either a large pancreatic resection (more than half) or severe postoperative sepsis. The three with normal responses (Cases 3, 8, and 10) had minimal pancreatic trauma.

Thus in this very small series pancreatic damage might account for the findings. This does not, however, exclude the idea of a common pathogenesis between insulinomas and diabetes. If the natural product of islet cell insulin in these patients was poor they would presumably be more sensitive to pancreatic damage than other people. Similarly, excessive "stimulation" of the islets would have been necessary to maintain normal glucose tolerance, and one might speculate that this stimulation gave rise to the insulinoma originally, as suggested in the diabetic mice. As pure hypothesis this would fit the facts of this study.

One patient (Case 9) is of interest in that she had no postoperative sepsis, but did have a blind distal pancreatectomy. Her insulin response was poor. If the diabetic tendency is associated with pancreatic damage this might be a further argument against blind distal pancreatectomy (Mengoli and Le Quesne, 1967).

\section{HYPOGLYCAEMIC ENCEPHALOPATHY}

Brain damage after hypoglycaemia is well documented (Jones, 1947; Courville, 1957; Etheridge and Millichap, 1964; Ingram et al., 1967). It resembles brain damage due to anoxia, and this may be due to the fact that glucose and oxygen are both necessary for cerebral cell function (Courville, 1957). Absence of either leads to damage in the same groups of cerebral cells. The two patients in the present series who had clinical evidence of brain damage after hypoglycaemic attacks have already been mentioned. The clinical hemiplegia was reflected in a localized abnormality on E.E.G. in Case 9. In Case 10 the E.E.G. showed evidence of both generalized and localized abnormalities for which no obvious clinical correlation was found. This patient later had a recurrent insulin-secreting tumour removed. So far as the other patients are concerned it is not easy to draw any general conclusions from the electroencephalographic findings. They could be compatible with minimal previous brain damage, but it is difficult to say more than this. The degree of E.E.G. abnormality could not be clearly correlated with the severity of the preoperative hypoglycaemic history or with the abnormality of the insulin response.

\section{OTHER POINTS}

In comparison with the survey of Markowitz et al. (1961) no patients had gastrointestinal bleeds or proved peptic ulceration. One patient admitted to indigestion, but this was not troublesome and had been present for many years both before and after operation.

I would like to thank Mr. M. A. Birnstingl for encouragement and advice with the preparation of this paper, together with Dr. K. A. Black and the other consultants at St. Bartholomew's Hospital who allowed me to study patients under their care; Dr. Vincent 
Marks and his staff at the Group Laboratories, Epsom Hospital, for the insulin result;, control values, and much help and encouragement; and Dr. J. H. Margerison and Mrs. P. Levi for taking and interpreting the electroencephalograms. Help with the statistics was given by Mr. M. Curwen at Guy's Hospital, and the manuscript could not have been drawn up without the unfailing help of Miss E. Arthur, of St. Albans City Hospital. Finally, many nurses and students helped to collect the data and all are gratefully acknowledged.

\section{References}

Bickel, G., Mozel, J. J., and Jaundry, R. (1935). Bulletins et Mémoires de la Socièté des IIopitaux de Paris, 51, 12.

Bielchowski, F. (1932). Klinische W'ochenschrift, 11, 1491.

Breidahl, H. D., Priestley, J. T., and Rynearson, E. H. (1955). Annals of Surgery, 142, 693 .

Cattell, R. B., and Warren, K. W. (1953). Surgery of the Pancreas. Philadelphia, Saunders.

Conn, J. W. (1946). Proceedings of the Diabctes Association, 5, 79.

Courville, C. B. (1957). Archives of Neurology and Psychiatry, 78, 1.

Etheridge, J. E., and Millichap, J. G. (1964). Neurology (Minneapolis), 14, 397.
Gittler, R. D., Zucker, G., Eisenger, R., and Stolter, N. (1958). New England fournal of Medicine, 258, 932.

Hales, C. M., and Randle, P. J. (1963). Lancet, 1, 200

Ingram, T. T. S., Stark, G. D., and Blackburn, Ivy. (1967). Brain, 90, 851. Izzo, J. L., Schuster, D. B., and Engle, L. E. (1953). Diabetes, 9, 93.

Jones, G. M. (1947). American Fournal of the Medical Sciences, 213, 206.

Klinik, D. D., Zalme, E., and Knowles, H. C. (1967). Archives of Internal Medicine, 119, 211.

Knight, P. O. (1967). Southern Medical fournal, 60, 119.

Laroche, G. P., Ferris, D. O., Priestley, J. T., Scholz, D. A., and Dockerty, M. B. (1968). Archives of Surgery, 96, 763 .

Like, A. A., Steinke, J., Jones, E. E., and Cahill, G. F. (1965). American Fournal of Pathology, 46, 621.

Markowitz, A. M., Slanetz, C. A., and Frantz, Virginia K. (1961). Annals of Surgery, 154, 877.

Marshall, S. F. (1958). Surgical Clinics of North America, 38, 743.

Mengoli, L., and Le Quesne, L. P. (1967). British fournal of Surgery, 54, 749 .

Moss, N. H., and Rhoads, J. E. (1960). Surgical Diseases of the Pancreas, ed. J. M. Howard, and G. L. Jordan, p. 321 . London, Pitman.

Priestley, J. T. (1962). Annals of the Royal College of Surgeons of England, 31, 211.

Remine, W. H., Scholz, D. A., and Priestley, J. T. (1960). American fournal of Surgery, 99, 413 .

Schumacker, H. B. (1940). Annals of Surgery, 112, 177

Schumacker, H. B. (1940). Annals of Surgery, 112, 177.
Søgaard, O. L., and Aargard, P. (1968). Danish Medical Bulletin, 14, 1.

Soper, R. T., Koch, T. H., Gius, J. A., and Liechty, R. D. (1968). Fournal of the Iowa Medical Society, 58, 579.

Van Der Sar, A., Bosschieter, E., Hugenholtz, M. J., and Van Der Hoeven, L. (1956). Documenta de Medicina Geographica et Tropica, 8, 85.

\title{
Paracetamol and Renal Damage
}

\author{
O. M. EDWARDS, PAULINE EDWARDS， E. C. HUSKISSON， R. T. TAYLOR
}

British Medical fournal, 1971, 2, 87-89

\section{Summary}

Renal function was assessed in 18 patients who had consumed 2 to $30 \mathrm{~kg}$ of paracetamol. No relationship was found between the total amount of paracetamol taken and any aspect of renal function studied. No pa:ient had clinically significant renal impairment. Thirteen of the patients showed no significant deterioration of renal function over a period of about one year during which they consumed an additional mean $2 \mathrm{~kg}$ of paracetamol.

\section{Introduction}

In recent years it has become clear that renal damage may be caused by consuming large amounts of analgesic mixtures. Because most of the affected patients have taken preparations containing phenacetin, this substance has been particularly implicated. Suspicion has also fallen on paracetamol, because it is a metabolic product of phenacetin. Two cases of nephropathy associated with paracetamol consumption have been reported (Krikler, 1967; Kerr, 1970). Kincaid-Smith (1969) noted that patients with analgesic nephropathy, which she attributed to phenacetin, failed to improve as expected

\section{Westminster Hospital, London, S.W.1}

O. M. EDWARDS, M.B., M.R.C.P., Research Registrar, Metabolic Unit PAULINE EDWARDS, M.в., Research Registrar, Metabolic Unit

E. C. HUSKISSON, M.B., M.R.C.P., Research Registrar, Rheumatology Department

R. T. TAYLOR, M.B., M.R.C.P., Senior Registrar when analgesic treatment was continued with paracetamol and aspirin in combination. On the basis of this evidence Koutsaimanis and de Wardener (1970) suggested that the use of paracetamol should be restricted by making it available only on prescription.

Paracetamol is widely used, low toxicity and absence of gastric irritation making it particularly suitable for patients with rheumatic diseases. A number of patients attending the rheumatism clinic at Westminster Hospital have consumed large amounts of paracetamol regularly; renal function has been studied in these patients to determine whether or not there is evidence of renal damage resulting from prolonged ingestion of paracetamol.

\section{Patients and Methods}

The 18 patients studied had all consumed at least $1 \mathrm{~g}$ of paracetamol daily for at least a year. Total drug consumption was determined from the patient's history with the aid of prescribing records. Schirmer's (1903) test of lachrymal secretion was performed, a value of less than $5 \mathrm{~mm}$ being taken as positive and indicative of Sjögren's syndrome.

During admission to hospital for 36 hours three blood samples were taken for estimation of urea and the mean value was calculated. Haemoglobin and bicarbonate levels were measured on the first sample. Two midstream specimens of urine were collected and cultured for organisms; the centrifuged deposit was examined for white cells and casts. Urine was collected during the first 24 hours for measurement of protein and creatinine excretion. During the first six hours a urinary acidification test was performed. Gelatin-coated ammonium chloride capsules $(0.1 \mathrm{~g} / \mathrm{kg}$ body weight) were given with water during the first hour, and $\mathrm{pH}$, total acidity, titratable acidity, and ammonium excretion were determined in the urine sample collected between the fourth and sixth 